\title{
The development of prospective memory in children: An executive framework
}

\author{
Caitlin E.V. Mahy ${ }^{a, *}$, Louis J. Moses ${ }^{b}$, Matthias Kliegel ${ }^{c}$ \\ a Department of Psychology, Brock University, St. Catharines, ON, Canada \\ ${ }^{\mathrm{b}}$ Department of Psychology, University of Oregon, Eugene, OR, USA \\ ${ }^{\mathrm{c}}$ Department of Psychology, University of Geneva, Geneva, Switzerland
}

\section{A R T I C L E I N F O}

\section{Article history:}

Received 4 March 2013

Revised 31 July 2014

Available online 22 August 2014

\section{Keywords:}

Prospective memory development

Executive function

Model

Intention

Delay

Ongoing task

\begin{abstract}
A B S T R A C T
Prospective memory (PM), the ability to remember to carry out one's intentions in the future, is critical for children's daily functioning and their ability to become independent from caregivers. This review assesses the current state of research on children's prospective memory. Using an executive functioning framework the literature can be organized into studies examining four factors that influence PM. We discuss studies that have manipulated the nature of the intention, the content or length of the retention interval, the nature of the ongoing task, and the nature of the PM cue. Further, we propose a model that attempts to account for the development of PM across childhood based on advances in executive control. Finally, we suggest promising future directions for research.
\end{abstract}

(c) 2014 Elsevier Inc. All rights reserved.

Orientation toward the future is thought to be a uniquely human characteristic. Our ability to think about, anticipate, and plan for the future sets us apart from our recent primate ancestors (Atance \& O'Neill, 2001; Donald, 1991). Orientation to the future is critical in daily life in situations ranging from academic performance (e.g., studying for an exam instead of attending a party) to financial planning (e.g., saving up for a home) to social functioning (e.g., remembering to meet a friend after work). One central aspect of future orientation is prospective memory (PM) defined as memory for activities to be performed in the future (Einstein \& McDaniel, 1990). In order to lead a productive life independent from others, one must develop the ability to remember to carry out planned intentions at a later time. Further, these intentions must be accomplished despite the presence of other ongoing

\footnotetext{
* Corresponding author. Address: Department of Psychology, Brock University, 500 Glenridge Avenue, St. Catharines, ON, Canada L2S 3A1. Fax: 905-688-6922.

E-mail address: caitlin.mahy@brocku.ca (C.E.V. Mahy).
} 
activities that may capture attention and so interfere with realizing these delayed intentions. In the review that follows we review evidence for the role of executive processes in four key components of a PM task, describe a developmental model of PM that is driven by executive processes, and suggest fruitful directions for future work.

\section{Prospective memory and its measurement}

PM is distinct from retrospective memory (RM), defined as memory for information or events from the past. Whereas externally prompted retrieval is typically a critical feature of retrospective memory, prospective memory is more often characterized by self-initiated retrieval processes (Craik, 1983) and preparatory processes such as monitoring (e.g., Smith, 2003). Of course, RM processes are important in PM, as individuals must remember what they must do as well as when they must do it. Indeed, many researchers have suggested that successful PM combines memory processes (remembering the content of the intention; a retrospective component) with executive processes (executing the action at the appropriate time; a prospective component; e.g., Ellis, 1996; Kliegel, Brandenberger, \& Aberle, 2010; Kliegel, Martin, McDaniel, \& Einstein, 2002; McDaniel, Glisky, Guynn, \& Routhieaux, 1999; Smith, Bayen, \& Martin, 2010; Zöllig et al., 2007).

An important conceptual distinction is that between time-based and event-based PM (e.g., Einstein \& McDaniel, 1990). Time-based PM requires the completion of an action at a certain time or after a specific amount of time has passed (e.g., pass a message to a colleague in two hours or at 4:15 pm), whereas event-based PM requires an action to be carried out after a certain event occurs (e.g., pass a message on when you see a colleague).

To mimic the demands of ongoing activities in daily life, a typical experimental PM paradigm has two main parts: a PM task and an ongoing task (OT; Einstein \& McDaniel, 1990). The PM intention is usually an action the participant is asked to carry out when a particular stimulus is present or after a certain amount of time has passed. The OT provides a context for the PM action and fills the intervals between the appearances of the prospective target events. For example, an individual may be asked to complete a lexical decision task as an OT but they might also be told to press a particular button when an animal word appears. After instructions are given regarding the OT and the prospective action, there is typically a period of delay in which the prospective stimulus does not appear. Often, this period is filled with another task that is not related to the OT or the prospective action (i.e., an unrelated, filler task) in order to provide time for some forgetting to occur (e.g., Brandimonte \& Passolunghi, 1994; Hicks, Marsh, \& Russell, 2000). Once this retention or delay interval is over, the OT begins and the PM cues appear within it.

\section{Why is it important to study prospective memory and its development?}

There are many reasons to study PM and its early development. First, a majority of adults' daily memory errors appear to be prospective (e.g., forgetting to put out the garbage on pickup day) rather than retrospective (e.g., forgetting the name of a new colleague; Smith, Della Sala, Logie, \& Maylor, 2000). According to a diary study, Terry (1988) found that $70 \%$ of memory errors made by university students are prospective in nature. The majority of forgetting had to do with neglecting to perform an action, to bring something to an event, or absentmindedness rather than forgetting facts, names, or other information known in the past. Naturalistic studies such as these have not been conducted with children but laboratory studies indicate high rates of forgetting in both experimental and quasinaturalistic PM tasks (e.g., Guajardo \& Best, 2000; Mahy \& Moses, 2011; Somerville, Wellman, \& Cultice, 1983).

Second, the ability to independently carry out a future intention reliably seems largely beyond the abilities of infants and toddlers (see Kliegel \& Jäger, 2007). Instead, PM in this period is heavily scaffolded by parents and other caregivers who often give helpful reminders that aid children's PM. By the time children reach school age, however, they are expected to be able to remember to carry out some of their self-formed intentions as well as future tasks assigned to them by others: For example, remembering to bring a permission slip for a field trip home for a parent to sign or remembering to bring an assignment back to school on its due date. If a child fails to complete tasks such as these, their 
academic performance will suffer. Forgetful children are thus at an academic disadvantage, even though they may in other respects be just as academically competent as other children.

Finally, beyond the academic realm, failures in PM may have serious negative consequences for children such as putting oneself in danger (e.g., forgetting to put on a bicycle helmet) or compromising social relationships (e.g., forgetting to bring a present to a friend's birthday party). In fact, it has been suggested that PM failures especially impact interpersonal relationships because they are often attributed to the unreliability of the individual rather than the unreliability of the individual's memory (Brandimonte \& Ferrante, 2009). This is in sharp contrast to errors in retrospective memory that are not often seen as shortcomings of character, but simply attributed to poor memory for past events or facts.

\section{Age-related changes in children's prospective memory}

Developmental increases in PM have been clearly documented using both experimental and naturalistic PM tasks (e.g., Ford, Driscoll, Shum, \& Macaulay, 2012; Guajardo \& Best, 2000; Kliegel \& Jäger, 2007; Kvavilashvili, Messer, \& Ebdon, 2001; Mahy \& Moses, 2011; Somerville et al., 1983; Kerns, 2000; Shum, Cross, Ford, \& Ownsworth, 2008). In addition, lifespan studies show increases in PM performance throughout childhood followed by peak performance in early adulthood and then declines in middle and old ages (Zimmermann \& Meier, 2006; Zöllig et al., 2007). See Figure 1 for a schematic of all published child PM studies to date.

\section{Mechanisms driving developmental change in prospective memory}

Many factors likely contribute to the rather extended developmental trajectory of PM from very early in childhood and into adolescence. First, retrospective memory processes are clearly implicated in increases in PM performance as studies have shown that PM failures in 2-year-olds are often due to memory errors surrounding the content of the intention (Kliegel \& Jäger, 2007), and that increases in retrospective memory account for some differences in PM performance in middle childhood (Smith et al., 2010; Zöllig et al., 2007).

Second, meta-memory develops over the early years of childhood (see Schneider, 2008) and knowledge of memory strategies could well promote better PM performance. Metamemory has an important influence on the development of retrospective memory (e.g., Bjorklund, 1987; Schlagmüller \& Schneider, 2002; Schneider, 1986). Yet, little work has investigated the possibility that advances in understanding memory strategies or other aspects of metamemory result in superior PM performance (although see Kvavilashvili \& Ford, 2014).

Third, episodic foresight is another skill that likely contributes to PM development, as the projection of the self into future episodes could be a helpful strategy in preparation for carrying out a PM task. Episodic foresight could thus be particularly helpful to the intention formation component of PM. That said, episodic foresight has not been consistently shown to relate to PM performance across childhood (Atance \& Jackson, 2009; Nigro, Brandimonte, Cicogna, \& Cosenza, 2014).

Fourth, children's time-relevant skills should play some role in time-based PM tasks. Surprisingly, however, children's time estimation skills have not been found to relate to time-based PM performance in typically developing children or children with ADHD (Mackinlay, Kliegel, \& Mäntylä, 2009; Talbot \& Kerns, 2014). On the other hand, children's time monitoring ability has been repeatedly shown to relate to such performance (see Kerns, 2000; Voigt, Aberle, Schonfeld, \& Kliegel, 2011).

Finally, and we would argue, most importantly, executive processes are likely a major driving force in PM development. EF is an umbrella term for abilities involved in the conscious control of thought and action including working memory, inhibitory control, shifting, planning, and monitoring (Zelazo, Carlson, \& Kesek, 2008). The ability to flexibly modify thought and action, we suggest, is key to successfully remembering to fulfill one's intentions and is thus one of the more promising mechanisms responsible for advances in PM (e.g., Ellis, 1996; Kliegel et al., 2002; Kliegel, Phillips, Lemke, \& Kopp, 2005). In what follows, we briefly summarize the development of EF during childhood, review evidence suggesting that EF plays an important role in PM development, and then describe how various facets of EF could be involved in components of PM tasks. 


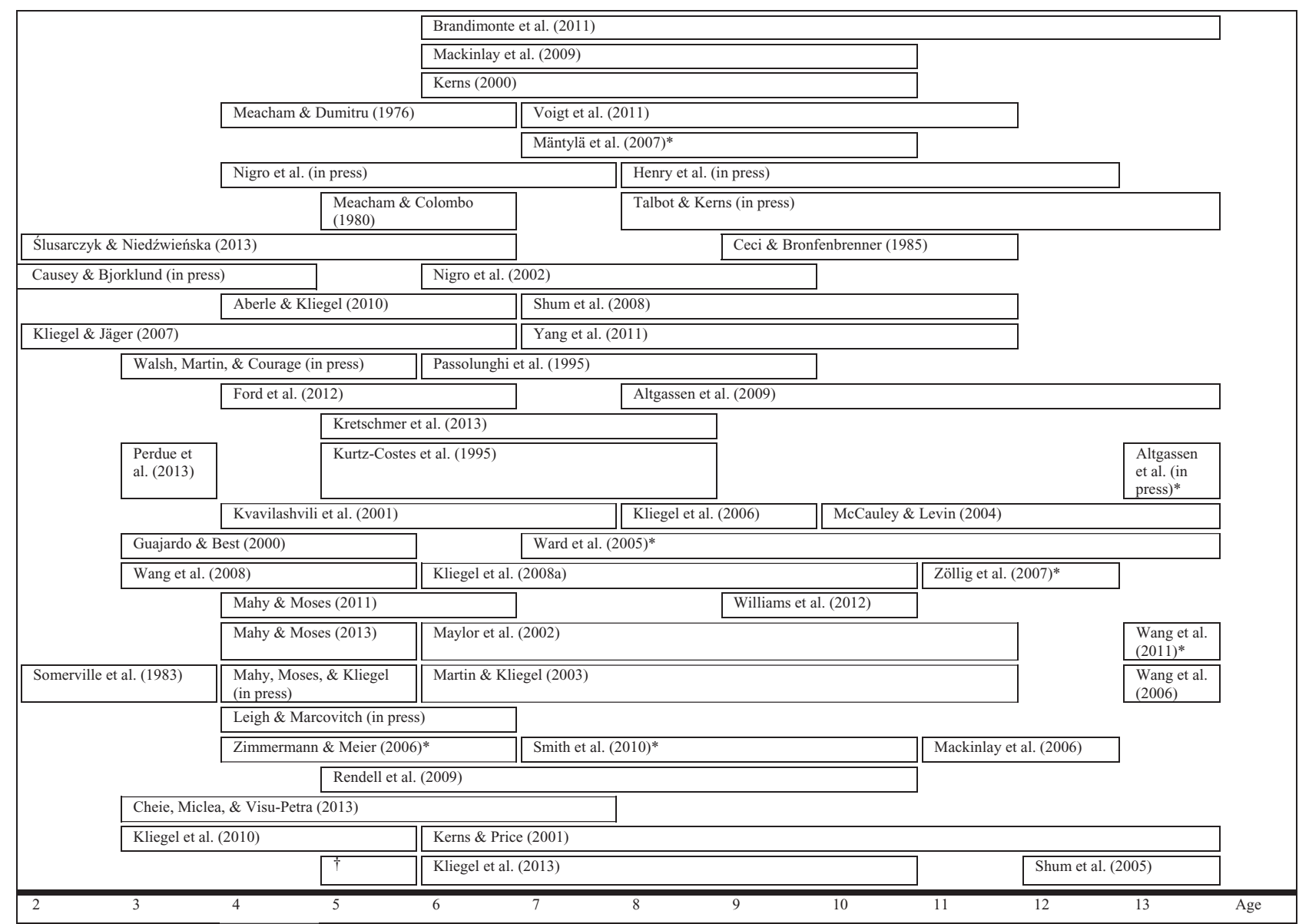

$*=$ studies that also include adult participants ${ }^{\dagger}=$ Kvavilashvili \& Ford (in press)

Fig. 1. All available prospective memory studies on children. $\left({ }^{*}\right)$ Studies that also include adult participants; (†) Kvavilashvili and Ford (2014). 


\section{The development of executive function}

Executive functions develop rapidly in the early childhood years (see Carlson, 2005; Davidson, Amso, Anderson, \& Diamond, 2006; Garon, Bryson, \& Smith, 2008; Munakata, Snyder, \& Chatham, 2012; Zelazo, Carter, Reznick, \& Frye, 1997) but continue to develop across adolescence and into early adulthood (see Best \& Miller, 2010 for a review). Advances in executive control rely on development of the prefrontal cortex, which slowly matures over childhood and adolescence and reaches maturity in the early 20s (e.g., Anderson, Anderson, Northam, Jacobs, \& Catroppa, 2001; Blakemore \& Choudhury, 2006; De Luca et al., 2003; Huizinga, Dolan, \& van der Molen, 2006). Executive ability is evident in children as young as 2 on tasks such as reverse categorization, gift delay tasks, and Stroop tasks (Carlson, 2005) that tap working memory, attention, inhibition, planning, and shifting.

The diversity or unity of specific EFs is still under debate (see Huizinga et al., 2006; Lehto, Juujärvi, Kooistra, \& Pulkkinen, 2003; Lee, Bull, \& Ho, 2013; Miyake et al., 2000; Miyake \& Friedman, 2012) as three EF factors (working memory/updating, inhibition, set-shifting) have been found in adults (Miyake et al., 2000) but several studies using confirmatory factor analysis have found EF to be a unitary construct in the preschool years (Hughes, Ensor, Wilson, \& Graham, 2009; Wiebe, Espy, \& Charak, 2008; Wiebe et al., 2011; Willoughby, Blair, Wirth, \& Greenberg, 2010). Broadly speaking, however, executive functions show somewhat differential developmental trajectories across childhood. Although in very early childhood these executive functions may be undifferentiated, they may become increasingly specialized during the later childhood years (Lee et al., 2013). Next, we discuss the developmental trajectories of working memory, inhibition, and set shifting.

\section{Working memory}

Even though toddlers can show basic working memory by holding a location of a treat in mind in the multi-location search task (Carlson, 2005), working memory continues to develop during the preschool years and into middle childhood. Working memory components are in place by 4 years of age (Alloway, Gathercole, \& Pickering, 2006) and show development from 4 years old into adolescence (Gathercole, Pickering, Ambridge, \& Wearing, 2004). Lee et al. (2013) found evidence for a steady increase in updating and working memory capacity from 6 to 15 years. Others have suggested an even longer developmental trajectory of working memory extending well into young adulthood (Huizinga et al., 2006). Neuroimaging evidence suggests that increases in activation in frontal and parietal brain areas underlie the development of working memory capacity from later childhood (9 years) into late adolescence (18 years; Klingberg, Forssberg, \& Westerberg, 2002).

\section{Inhibition}

Early in the preschool years children are able to inhibit their desire for immediate gratification, and inhibit pre-potent verbal and motor responses (Carlson, 2005). Based on a large-scale study of 3- to 12-year-old children and young adults, Welsh, Pennington, and Groisser (1991) showed that organized search that required inhibitory control developed around age 10. Lee et al. (2013) found that between 6 and 15 years of age, there were age-related reductions in inhibitory cost with age for the Flanker task, a task that required children to indicate the direction of a central stimulus while ignoring flanking stimuli (Fan, McCandliss, Sommer, Raz, \& Posner, 2002), and for a child-friendly antisaccade task called the Mickey task (Nieuwenhuis, Ridderinkhof, Kok, \& van der Molen, 2000). In contrast, Lee and colleagues found stable inhibitory costs across age groups on a Simon task (see Davidson et al., 2006), which required children to reverse a pre-potent response pattern to a pair of stimuli. The maturation of the ventral fronto-striatal circuitry has been found to underlie the development of inhibitory control from 6 years old into adulthood (Durston et al., 2002; Luna, Padmanabhan, \& O’Hearn, 2010).

\section{Set-shifting}

Around 4 or 5 years of age, children begin to be able to pass the Dimensional Change Card Sort, a standard measure of set shifting during the preschool years (Zelazo, 2006). At this age, children can 
switch flexibly to use a new set of rules that conflict with a previous set of rules. Cognitive flexibility continues to develop between 7 and 9 years of age and is relatively mature by 12 years according to findings by Anderson (2002). However, Huizinga, Dolan, \& van der Molan (2006) showed that older children and adolescents show continued development of shifting into adolescence. Preschoolers' success in shifting was associated with inferior prefrontal activation (Moriguchi \& Hiraki, 2009) consistent with the finding that mature shifting relies on inferior frontal and parietal regions as well as superior temporal regions in adults (Smith, Taylor, Brammer, \& Rubia, 2004).

Broadly speaking, PM and EF development follow a similar developmental timetable, opening up the possibility that advances in EF may be related to advances in PM. For example, notable agerelated improvement in PM occur from 2 years of age to 6 years of age (Kliegel \& Jäger, 2007; Mahy \& Moses, 2011), a time period in which rapid improvement in executive abilities also takes place (Carlson, 2005). It is possible that these advances in executive ability are driving developmental changes in children's prospective memory, although this question is just beginning to be examined empirically (Kretschmer, Voigt, Friedrich, Pfeiffer, \& Kliegel, 2013; Mahy, Moses, \& Kliegel, 2014).

\section{Executive framework}

We propose an EF framework for the development of PM according to which controlled executive processes are critical to PM and that different EFs (e.g., working memory, inhibition, set-shifting, planning, and monitoring) play more important roles than others at certain stages of PM. Our theoretical framework draws upon (a) existing theoretical models that explicitly suggest a role for controlled executive processing in PM in adults, and (b) empirical evidence that EF plays an important role in adult PM performance.

\section{Theoretical models of prospective memory}

Current theoretical frameworks for PM in adults ascribe differential weight to the controlled, executive processes involved in PM. The multiprocess model (McDaniel \& Einstein, 2000) proposes that associative processes are involved in PM but that controlled processes also operate if the task is cognitively demanding such as when the ongoing task is difficult, cue salience is low, or when PM cues are not focal to the processing of ongoing task items. The model also proposes that controlled processing may occur more frequently in individuals with personality characteristics such as higher rumination. In contrast, the preparatory attentional and memory processes (PAM) model (Smith, 2003; Smith \& Bayen, 2004) suggests that controlled processes such as monitoring are always operating during PM prior to the presentation of the PM cues. Smith and colleagues documented that there is often a trade-off between prospective memory and ongoing task performance indicative of controlled processes operating for the detection of the PM cues. Unlike the multiprocess model, the PAM model posits little role for automatic processes.

Despite their differences, both models of PM suggest that controlled, executive processes play important roles in PM, at least under certain circumstances. Neither model, however, addresses whether automatic or controlled processes drive the development of prospective memory. Although the models are useful for making predictions about what types of task manipulations might impact PM, they are silent with respect to the mechanisms of PM development in childhood. In contrast, the framework proposed below delineates specific EFs as important for specific phases of PM and makes predictions about when these executive processes might be especially important to PM development.

\section{Executive function and prospective memory in adulthood}

Consistent with these two executive models, a large body of behavioral and neuroimaging work suggests an important role for EF in PM functioning in adults. For example, adults with larger working memory capacity are better able to adjust their attention allocation after experience with the PM task (Hicks, Marsh, \& Cook, 2005). Further, more than 50\% of the variance in adult performance on a complex prospective memory task was predicted by their executive abilities, particularly planning and cognitive flexibility (Kliegel et al., 2002). Similarly, several manipulations of executive control in 


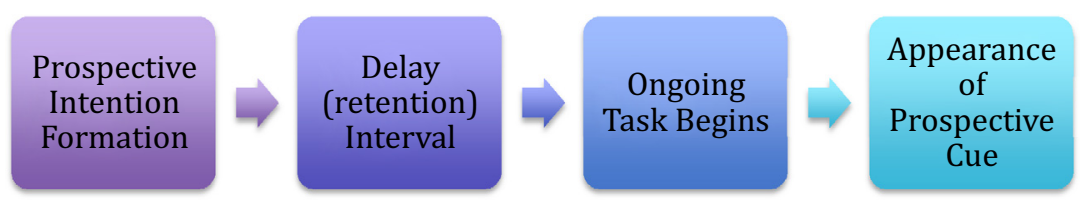

\begin{tabular}{|} 
Working Memory: Maintaining the intention \\
Kretschmer et al. (2013) \\
Mahy \& Moses (2011) \\
Mahy \& Moses (in press) \\
\end{tabular}

Mind Monitoring: Refreshing the
prospective intention
Mahy \& Moses (in press)
Set shifting: flexible switching between prospective action and ongoing task Kerns (2000)

External Monitoring: Detecting the prospective cue

Mahy, Moses, \& Kliegel (in press) Kliegel et al. (2013)

Inhibition: overcome pre-potent response to treat target like an ongoing distracter

Kvavilashvili, Messer, \& Ebdon (2001) Wang et al. (2008)

Fig. 2. The role of specific executive functions in task components of a prospective memory task and studies that support the involvement of the process.

PM tasks revealed that planning and monitoring appear to be critical to successful event-based PM (Marsh \& Hicks, 1998). In addition, in an aging study, age-related differences in PM were mediated by processing speed, inhibitory control, and working memory (West \& Craik, 2001). Finally, several studies using functional neuroimaging and event-related potentials have indicated the important role of various regions in the prefrontal and parietal cortices in prospective memory processes suggesting that working memory, inhibition, and attention switching between external events and internal thought processes are likely operating during prospective remembering (Bisiacchi, Schiff, Ciccola, \& Kliegel, 2009; Burgess, Quayle, \& Frith, 2001; Czernochowski, Horn, \& Bayen, 2012; Martin et al., 2007; Mattli, Zöllig, \& West, 2011; McDaniel et al., 1999; McDaniel, LaMontagne, Beck, Scullin, \& Braver, 2013; Okuda et al., 1998; Simons, Schölvinck, Gilbert, Frith, \& Burgess, 2006; West, 2011; West \& Covell, 2001; Zöllig et al., 2007).

\section{The role of executive function in prospective memory}

Our framework highlights four components of EF that we think are central to the development of PM. These include three aspects of EF that have been consistently identified as core executive processes in factor analyses: working memory, inhibition, and set shifting (e.g., Miyake et al., 2000). We also include monitoring, specifically internal monitoring of mental states such as intentions and external monitoring of the environment, both of which have been suggested to play important roles in adults' PM and more broadly in cognition (e.g., Burgess, Dumontheil, \& Gilbert, 2007; Smith, 2003). We next consider what roles these EFs may play in successful PM performance (see Fig. 2). 
First, working memory is involved in maintaining or refreshing the content of the prospective intention that needs to be brought to mind each time the prospective cue appears. Hicks et al. (2005) suggested that intentions can fade in and out of the focus of working memory over time as in Cowan's model of the focus of working memory (Cowan, 1995, 2005). Individuals with stronger working memory skills may be able to maintain prospective intentions in their focus of attention for longer periods of time or bring them back to focus more quickly, yielding benefits to PM performance.

Second, inhibition is required to interrupt performance of the OT (the pre-potent response) in order to activate the novel PM response. Many elements of the PM task alter the amount of inhibition needed to complete the prospective intention. For example, PM cues low in salience would require higher levels of inhibition of the OT in order to be detected. In addition, if the PM cue is placed at the end of the OT rather than interrupting it, less inhibition should be required.

Third, set shifting plays a role in PM because participants need to switch back and forth between the OT and the PM task as a function of the presence of the PM cue. In a typical PM paradigm there are relatively few appearances of the PM cues (no more than $10 \%$ of trials) in order to ensure that PM is being recruited rather than an active search process more typical of a vigilance task (Brandimonte, Ferrante, Feresin, \& Delbello, 2001). As a result, PM paradigms have significant task-switching demands because the PM targets are rare events, making it increasingly difficult to shift away from the wellpracticed OT to carry out the PM task. This shifting back and forth between the OT and PM tasks may be especially challenging when different levels of processing are required for each task.

Fourth, two kinds of monitoring are important for PM. Clearly, the external environment must be monitored for the appearance of the PM cue, but individuals must also internally monitor their own intentions in order to remember the content of the intention and to carry it out at the appropriate time. This distinction between external monitoring of the environment and internal monitoring of mental states and processes has been supported by neural evidence showing that the anterior PFC supports the biasing of attention between external events such as detection of the PM cue in the environment and internal thought processes such as maintaining the prospective intention (see Simons et al., 2006). Both types of monitoring can be manipulated in PM paradigms although most manipulations to date have focused on varying the amount of monitoring needed to detect the external PM cue and on the impact of this monitoring as assessed by PM-OT tradeoffs (Smith, Hunt, McVay, \& McConnell, 2007). Monitoring can occur during both the delay (internal monitoring) and the OT (internal or external monitoring). Individuals who monitor more frequently or consistently may show better PM performance.

Like the multiprocess framework, our proposal does not imply that controlled processes must always operate during PM, but rather that (a) children's PM should be worse in paradigms with high EF requirements and better in paradigms with low EF requirements, and (b) when executive demands are high, executive abilities should predict individual differences in PM performance.

\section{Review of developmental literature}

Several taxonomies of core aspects of PM have been proposed (Brandimonte, 1991; Kliegel, Mackinlay, \& Jäger, 2008b; Kvavilashvili, Kyle, \& Messer, 2008). Our own framework focuses on factors that affect PM via EF and more explicitly recognizes the role of the OT in PM performance (see also Kliegel, Ropeter, \& Mackinlay, 2006). We suggest that the nature of the intention, the length and nature of the delay before the PM task begins, the nature of the OT, and the nature of the prospective cues are four key factors that potentially affect children's PM via their impact on EF. Our taxonomy focuses on two explanatory levels: task factors or demands and individual differences. Task characteristics and individual differences affect the level of executive demand or the availability or accessibility of children's executive resources, respectively.

Importantly, these factors all vary in the extent to which they implicate specific EFs. The purpose of this review is to summarize developmental research relevant to these four components of the PM task, to integrate this research into a novel framework emphasizing the role of EF in PM, and to offer directions for future research to motivate further work in this understudied field. 


\section{Factors that influence PM}

\section{Nature of the intention}

The nature of the prospective intention has been one of the most studied aspects of children's PM. Many aspects of an intention could have an impact on PM; the level of interest or motivation to carry out the intention, the number of intentions to be remembered, the complexity of the intention, and how much emphasis is placed on the intention.

\section{Motivation}

Motivation to perform a task has a significant impact on children's cognitive performance (e.g., Carlson, Davis, \& Leach, 2005; Kerr \& Zelazo, 2004; Hongwanishkul, Happaney, Lee, \& Zelazo, 2005) and PM is no exception to this rule. An intention that is highly motivating requires less working memory resources and inhibitory control, as children will be more interested in the PM task and it will likely be more easily activated in memory. The impact of motivation on children's PM has been examined in two ways: (1) assigning children inherently motivating intentions (e.g., to remember to remind an experimenter to give them stickers) versus mundane intentions (e.g., to remember to remind an experimenter to change a sign), and (2) by using incentives or rewards to increase children's motivation to carry out the PM task (e.g., offering children candy each time they carry out their intention).

First, we review studies that have examined the inherent motivation of the intention. In a naturalistic study with 2- to 4-year-olds, Somerville et al. (1983) found that children remembered to perform high-interest intentions (e.g., reminding their mother to buy ice cream) more than lowinterest intentions in a naturalistic task (e.g., reminding their mother to turn off the sprinkler). Similarly, Causey and Bjorklund (2014) found that 2- to 4-year-olds were more successful in remembering to get a sticker for themselves at the end of the session (high interest task) than to remember to turn a sign over (low interest task). Additionally, highly motivating intentions (i.e., remembering to ask an experimenter for candy or to remember to take a sticker when they were finished playing with blocks) were necessary for 2-year-olds to perform well on a naturalistic PM task compared to low motivation intentions (i.e., remembering to put away their crayons after drawing or to tell the experimenter who was taking them home) and continued to facilitate performance across the entire preschool age range (Ślusarczyk \& Niedźwieńska, 2013). In addition, Kliegel et al. (2010) showed that 3-year-olds' PM was worse than that of 5-year-olds in a low-motivation condition where child had to remind the experimenter to write down their name on some documents but did not differ in a high-motivation incentive condition where children has to remind the experimenter to give them a present from a "magic box". Similar effects have been found with older children. In a classic experiment with 10and 14-year-olds, children were asked to perform sex-typed PM tasks, namely, remembering to remove cupcakes from the oven or to stop charging a motorcycle battery after 30 minutes (Ceci \& Bronfenbrenner, 1985). Boys checked the time more often in the battery charging task compared to the baking task whereas girls checked the time more often in baking task compared to the battery charging task suggesting that sex-typed tasks were potentially more engaging to children of this age and that this had an impact on their time monitoring behavior. Taken together, these results suggest that an inherently motivating intention may have the potential to boost PM performance throughout much of childhood.

Second, the effect of providing incentives or rewards for remembering to carry out certain noninherently motivating intentions (such as placing a card in a certain location) has also been examined. In the only study to do so, however, 3- and 5-year-old children's PM performance was not influenced by the presence of incentives (e.g., crackers, pretzels, pennies, or fruit chews for successful performance) in an experimental context, even though children reported that the presence of these incentives positively influenced their PM performance (Guajardo \& Best, 2000).

In sum, greater levels of inherent motivation to perform the PM intention lead to improved PM in children. In contrast, providing young children with incentives to remember mundane intentions does not appear to affect PM task performance, although the evidence is quite limited at this point. 


\section{Intention emphasis}

The extent to which carrying out the prospective intention is emphasized compared to performing the OT may affect PM. Emphasized intentions should require less inhibitory control to be activated and should therefore be easier to shift to than non-emphasized intentions. In adults, PM performance was better in a high emphasis condition in which participants were asked to concentrate on looking for the target word compared to a low emphasis condition in which they were told to focus on carrying out the OT (Einstein et al., 2005). As yet, there are no data from young children. However, adolescents benefit more from an instruction with emphasis on the PM task versus the OT than do young adults (Wang, Kliegel, Yang, \& Liu, 2006), suggesting that emphasis on the intention may also be helpful to younger children. The developmental difference between adolescents and adults can be explained by the greater maturity of adults' inhibition and set shifting compared to that of adolescents who are still developing these abilities.

\section{Number of intentions}

In principle, assigning more than one intention should result in worse PM, as multiple intentions impose a higher working memory load. In adults, increasing working memory load by assigning two intentions versus one (Hicks et al., 2005) or six intentions versus one (Einstein et al., 2005) impaired OT performance although it did not negatively affect PM. In contrast, in the only study of this kind with children, Mahy and Moses (2011) found no effect of the number of intentions (one versus two) on PM or OT performance in 4- to 6-year-olds. However, in the dual intention condition two continuous visual prospective cues were present while only one was present in the single intention condition. This difference may have prevented the emergence of a number of intentions effect.

\section{Intention complexity}

Intention complexity is an important factor to address as PM tasks in children's daily lives vary in complexity from relatively simple tasks such as remembering to bring a toy to a friend's house to more complicated intentions such as passing a message to a teacher about the dates of an upcoming family vacation. The working memory demands of complex prospective intentions are presumably greater and thus should negatively affect PM. Indeed, adults' PM was quite poor when they had to remember a highly specific and complex intention (such as telling an experimenter that a questionnaire 'must be drawn from file X, not from file Y' on a second experimental session; Nigro \& Cicogna, 2000). The authors suggest that low levels of PM performance were likely due to RM failures as many participants remembered they had to remind the experimenter but were not able to remember the exact nature of the intention. Developmental studies that involve a series of complex rules for the completion of the PM task have found age-related increases in PM performance between 7- and 10-years (Kliegel, Mackinlay, \& Jäger, 2008a; Martin \& Kliegel, 2003). However, complex intentions were not contrasted with a simple intention, as this was not the primary purpose of the studies. In order to better examine the impact of intention complexity on PM, such comparisons are a necessary next step.

\section{Intention encoding modality}

Encoding a prospective intention relies on attentional and working memory processes. Less demand should be placed on these processes when a link between the cue and action, or visual presentation of the prospective action, is provided at encoding. Passolunghi, Brandimonte, and Cornoldi (1995) conducted a series of experiments showing that younger children's (7- and 8-year-olds) PM benefited most when the prospective action was visually presented at encoding (e.g., a picture of a boat was presented when the PM task of pressing a key when the word 'boat' appeared was assigned), whereas older children's (10- to 11-year-olds) PM performance benefited most from enactment of the response (e.g., children were requested to press the key after the instruction to press a key when they saw the word 'boat' was introduced).

To summarize, children's PM is affected by the motivation to carry out the intention particularly when the motivation is inherent to the intention rather than related to rewards received for carrying out an intention, how much importance is placed on carrying out the intention compared to the ongoing task, the complexity of the intention, and the intention encoding modality. Conditions that lower executive demands required for processing the PM intentions, such as those discussed earlier, result in 
better PM performance early in development presumably because EF skills are underdeveloped during childhood.

\section{Nature of delay}

PM tasks almost always involve a delay of some kind in order to allow for some forgetting (e.g., Einstein \& McDaniel, 1990). Indeed, some have argued that this filler period is necessary to induce forgetting and to distinguish PM tasks from simple vigilance tasks (e.g., Brandimonte, Ferrante, Feresin, \& Delbello, 2001, while others have argued that the delay interval is unnecessary to include prior to the OT (Kvavilashvili \& Erskine, 2010). In any event, a delay of some kind is certainly reflective of everyday life in which PM intentions often need to be carried out long after they are initially formed. Importantly, several characteristics of the delay affect adults' and children's PM (Hicks et al., 2000; Mahy \& Moses, 2011; Martin, Brown, \& Hicks, 2011; Nigro, Senese, Natullo, \& Sergi, 2002; Somerville et al., 1983), and these will be described next.

\section{Length of delay interval}

One might expect that PM would suffer after longer compared to shorter delays, given findings in the retrospective memory literature that document a forgetting curve in many areas including foreign language learning (Bahrick \& Phelps, 1987) and typing skills (Baddeley \& Longman, 1978) in adults, and story recall (Howe, 1991) and retention of word lists (Brainerd \& Reyna, 1998) in children. Interestingly, however, adults' PM has been found to actually improve with an increase in the retention interval from 2.5 to 15 minutes (see Hicks et al., 2000; Martin et al., 2011). Hicks and colleagues argued that a longer retention interval allows more opportunities to refresh and consolidate intentions compared to a shorter retention interval. Consistent with these adult findings, 5-year-olds' PM was better after a 5 minute delay compared to a 1 minute delay, whereas 4-year-olds' PM tended to get worse (Mahy \& Moses, 2011). Like adults, 5-year-olds may have been able to take advantage of a longer delay interval in order to monitor their intentions. In contrast, the younger children may have been unable to refresh their intentions, perhaps because of developmental limitations in cognitive monitoring. The delay interval can thus be viewed as both an opportunity for forgetting to occur by not maintaining the intention in the focus of one's working memory, but also an opportunity to monitor one's intention and keep it somewhat active in working memory.

That said, we would not expect performance to always improve over a delay even for older children. In that regard, Nigro et al. (2002) found that 7- to 11-year-olds' PM suffered with delay (15 versus 10 minutes) when the prospective task was time-based but not when it was event-based. In eventbased tasks external cues support remembering perhaps by prompting monitoring whereas in timebased tasks these supporting cues are often absent and one must rely entirely on self-initiated processes. The absence of external cues in time-based tasks likely contributes to increased forgetting at longer delays.

Delay has been investigated in a slightly different way in studies that employ a delay-execute PM task. One such task required 5- to 11-year-olds to delay their response after having seen the prospective cue (delay-execute condition) or to carry out the response immediately on seeing the cue (retrieve-execute condition). Children had worse PM in the delay-execute condition compared to the retrieve-execute condition (Rendell, Vella, Kliegel, \& Terrett, 2009). The delay-execute PM trials are similar to time-based PM tasks, as both require children to initiate an action after a period of time has passed rather than making a response when a PM cue appears. As with time-based tasks, the additional demands on self-initiated processes may impose a heavier executive burden than those imposed by traditional event-based tasks.

Delay is also likely to have a deleterious effect when it is much longer (hours or days as opposed to minutes). In these circumstances both children and adults are highly unlikely to continue to monitor their intentions. Consistent with this argument, Somerville et al. (1983) found in a parent report study that 2- to 4-year-olds were better at reminding their mothers to do something after a short delay (5-10 minutes) than after a very long delay (the following afternoon or next morning; 6-12 h). 
Nature of delay interval

In addition to delay length, it is critical to consider what is happening during the retention interval. In adults, a delay filled with a demanding short-term memory task or an undemanding motoric task negatively affected PM whereas a delay that was unfilled or filled with an undemanding verbal task did not (Brandimonte \& Passolunghi, 1994). Based on these results, adults' PM seems to be disrupted by delay activities that require more attentional resources or motor activity. Similarly, 4- and 5-year-olds performed worse on a PM task after completing a difficult visual working memory task, the self-ordered pointing task (see Hongwanishkul et al., 2005; Petrides \& Milner, 1982), during the delay interval compared to children who performed an easier version of the task (Mahy \& Moses, 2014).

These results can be interpreted within the cognitive monitoring hypothesis presented earlier in that children engaged in a more difficult task have fewer opportunities to think about their intentions, thus resulting in worse PM. Consistent with this hypothesis, adults who are given more breaks between activities (and therefore, more opportunities to refresh their intentions) in the delay interval show better PM than those who are given no breaks (Hicks et al., 2000). Also consistent with the hypothesis are findings that 5-year-olds' PM tended to be better following a delay interval filled with a reminder story about a forgetful spider than after a control story about a lazy alligator (Kvavilashvili \& Ford, 2014), but only for children who predicted they would remember to carry out the PM task. PM performance may have benefited from the reminder story for those children because the content of the story prompted them to think more often about the memory task they themselves would need to shortly complete.

In contrast to these findings, Meacham and Colombo (1980) found that intervening task difficulty did not affect 6- to 10-year-olds' PM performance. The easy intervening activity was a card game and the difficult intervening activity consisted of an interview developed to assess locus of control expectancies. It is unclear, however, the extent to which the intervening tasks in this study differed in difficulty as no objective measure of filler task performance was taken. Moreover, it is not obvious that these two filler tasks differed in executive difficulty and, if they did not, they do not speak to the monitoring hypothesis.

\section{Nature of ongoing task}

The main purpose of the OT is to provide a distracting activity in which the PM cues are embedded. The OT can differ in its difficulty and whether it has to be interrupted to complete the PM task. OT response latencies are often examined in order to detect tradeoffs between OT and PM task performance; slowing on the OT often occurs in order to carry out the PM task successfully. Alternately, maintaining good OT performance can result in less accurate or slower responses to the PM task. As noted earlier, the presence of PM-OT tradeoffs supports theories of PM, such as the PAM model (Smith, 2003) and the multiprocess framework (McDaniel \& Einstein, 2000): These theories posit that at least under some circumstances controlled executive processes are necessary for PM and a demanding OT should consume executive resources.

Difficulty of the ongoing task

Varying the working memory load of the OT by asking 3- to 5-year-olds to memorize items as they named them did not affect PM accuracy but did result in slower PM response times (Wang, Kliegel, Liu, \& Yang, 2008). In a recent study from our lab, OT difficulty was manipulated by asking 4- and 5 -year-olds to sort cards by matching categories or by opposite categories (Mahy et al., 2014). The manipulation had a significant impact on OT accuracy, with children who sorted cards by opposites having less accurate card sorting than those who sorted by normal categories. In addition PM performance was affected by OT difficulty when PM cues were of low salience, although not when they were of high salience. In a driving simulation study with 6- to 10-year-olds children had to push a button when they saw a flower pot at the side of the road (the PM task) while driving a car on a low versus high traffic road. PM performance was worse under high traffic conditions than under low traffic conditions (Kliegel et al., 2013). Similarly, school-age children's, adolescents', and adults' PM performance on a computerized lexical decision task in which they had to press a button when words were italicized (PM task) was found to be better with longer rather than shorter presentation times of OT stimuli 
(Ward, Shum, McKinlay, Baker-Tweney, \& Wallace, 2005). These various studies generally support the task difficulty hypothesis that increases in OT difficulty result in worse PM performance.

\section{Presence of ongoing task interruption}

Young children's PM generally declines when the OT must be interrupted in order to complete a prospective action compared to when it is completed immediately following the OT (e.g., Ford et al., 2012; Kliegel et al., 2008a; Kvavilashvili et al., 2001; Ślusarczyk \& Niedźwieńska, 2013; Wang et al., 2008). Wang et al. (2008) suggested that the interruption condition requires more inhibitory control than the non-interruption condition leading to worse PM performance, as young children struggle with inhibiting pre-potent responses. Similarly, Ślusarczyk and Niedźwieńska (2013) suggested that the youngest and oldest children in their sample were not differentially affected by a task interruption manipulation because their inhibitory ability was not yet developed or more highly developed, respectively, and therefore did not affect performance (younger children performed poorly in both conditions while older children did well in both conditions). In addition to inhibitory control, set shifting also likely plays a role in the effect of the task interruption condition: When the OT must be interrupted children need to discontinue the OT temporarily in order to carry out the PM task and then resume the OT once the prospective action is completed.

\section{Nature of cue}

To date, the nature of the prospective cue has been manipulated in four main ways: whether the cue is event- or time-based, whether an external cue is present during the PM task, the relative salience of the cue compared to the OT stimuli, and the focality of the PM cue.

\section{Event- and time-based cues}

As noted earlier, a key distinction in the PM literature is whether cues are events or whether the cue is a particular point in time. Most research on children has employed event-based measures of PM as young children have difficulty with time perception and clock reading. However, recently developed tasks such as driving simulation games in which gas levels must be monitored (Kliegel et al., 2013) or those in which an hourglass must be monitored (Aberle \& Kliegel, 2010) are time-based task that avoid this difficulty and have been used successfully with children as young as 5 and 6 years of age. Time-based tasks tend to be more difficult than event-based PM tasks (e.g., Yang, Chan, \& Shum, 2011). One likely reason for this difficulty difference is that time-based PM relies on additional monitoring of a clock or other time-keeping device whereas event-based PM cues appear within the child's immediate attention and therefore do not require extra monitoring.

\section{Presence of external reminders}

External cues may improve PM by making intentions more readily accessible and therefore requiring less inhibitory control in order to activate the prospective intention. Self-created external aids, such as writing the name of the prospective cue on a piece of paper and taping it to the computer, increased young and elderly adults' PM (Einstein \& McDaniel, 1990). Similarly, the presence of an external cue generally results in better PM performance in children. For example, having a picture of the PM target present during the OT improved 3- to 7-year-olds' PM performance compared to a condition in which no PM target was present (Cheie, Miclea, \& Visu-Petra, 2013; see also Meacham \& Colombo, 1980, for similar findings with 6- to 8-year-olds). In another sample of 3- to 5-year-olds, however, an external cue (a picture of the PM target) did not improve PM performance for reasons that are unclear (Guajardo \& Best, 2000). In a final study Kliegel and Jäger (2007) showed that 2- to 6-year-olds' PM was better when cue- and action-relevant external memory aids were present. They found that using a real apple (cue for the target) and a box on a table (cue for the action) in children's sight helped to remind children to hide the apple cards in the box when they appeared in the OT. However, because the 'memory aid' condition contained these two cues (both an apple and a box) and the 'no memory aid' condition had no cues, it is unclear whether the effect was due to the presence of one or both cues. 


\section{Cue salience}

The more unique or salient a prospective cue is compared to the OT items, the more successful children's and adults' PM performance. Salient cues should make shifting attention easier, reduce the demand for monitoring, and require less inhibition to activate the PM intention, resulting in better PM. In adults more salient non-word targets such as 'sone' or 'monad' that were dissimilar to the OT stimuli (e.g., concrete nouns) improved PM performance by a factor of 3 compared to word targets such as 'rake' or 'method' (Einstein \& McDaniel, 1990). In children, PM cues surrounded by a bright red border resulted in better PM performance in 4- and 5-year-olds compared to cues that, like the OT items, had no such a border (Mahy et al., 2014). Finally, in the driving simulation task described earlier, 6- and 7-year-olds' and 9- and 10-year-olds' PM was boosted by PM cues that were more distinct (many flower pots) compared to less distinct (a single flower pot) (Kliegel et al., 2013).

\section{Cue focality}

Cue focality has been manipulated in adult PM studies revealing that when prospective cues need to be processed in the same way as those already in the focus of attention during the OT, PM performance is better than when attention needs to switch to another dimension of the cue (e.g., Einstein et al., 2005; Kliegel et al., 2008a; Marsh, Hicks, \& Hancock, 2000; Scullin, McDaniel, Shelton, \& Lee, 2010). For example, a PM cue that requires words to be analyzed for meaning just as in the OT would be described as a focal-cue, whereas a PM cue that requires the color of the background to be analyzed while the OT requires word meaning to be analyzed would be described as a non-focal PM cue. Cue focality has been suggested as a key factor in whether controlled or associative processes are necessary for PM cue detection in the multiprocess framework (e.g., Einstein \& McDaniel, 1990), as non-focal cues require more controlled processes because the PM cue requires a different level of analysis.

In a study with adolescents and adults ages 13-20, there was no effect of age on PM when a focal cue was present but young adults performed better than adolescents and when nonfocal cues were presented suggesting that this ability improves with age (Wang et al., 2011). Most PM paradigms designed for younger children include focal cues that do not require a shift in attention to another dimension in order to detect the PM cue. For example, children are often asked to name items presented on cards but to perform a novel action when they see a specific kind of card such as an animal card (e.g., Kvavilashvili et al., 2001; Mahy \& Moses, 2011). Because children are already processing the semantic information of each item during the OT, detecting the animal is fairly easy, as it does not require shifting focus to a dimension other than semantic information. To the best of our knowledge, the only research to explicitly manipulate whether the cue is within or outside of focal attention in children found that 6- to 7- and 9- to 10-year-olds had better PM for focal cues compared to nonfocal cues in the driving simulation game (Kliegel et al., 2013). In this study children either had to detect PM cues already in the focus of their attention (a yellow car on the road) or cues that required shifting attention away from the OT for detection (a flowerpot on the side of the road). The effect of cue focality interacted with age such that younger children's PM suffered more than that of older children with cues outside of focal attention suggesting that limited executive resources make shifting attention to non-focal cues more challenging at earlier ages.

\section{Correlational studies of PM and executive function}

A growing number of studies have found moderate associations between EF and PM in children although the specifics vary from study to study. In 6- to 12-year-olds, time-based PM was related to inhibition, visual working memory, and set shifting after controlling for age (Kerns, 2000). In another study the majority of age-related variance in 7- to 12-year-olds' time-based PM was explained by planning and task switching ability (Mackinlay et al., 2009). Still other research has suggested that inhibition and updating, but not set shifting, were related to monitoring performance in a time-based PM task in school-aged children (Mäntylä, Carelli, \& Forman, 2007). In 8- to 9- and 12- to 13-year-old children, verbal fluency, working memory, inhibition, and cognitive flexibility significantly predicted eventbased PM above and beyond age (Shum et al., 2008). Therefore, the relation between EF and PM is 
fairly robust during middle childhood, although there are mixed findings about the role of various EFs in time- and event-based PM performance.

In 4- to 6-year-olds, working memory, but not inhibition, was related to event-based PM above and beyond age (Mahy \& Moses, 2011). In contrast, Ford et al. (2012) found that inhibitory control and working memory predicted variance in PM after age and receptive vocabulary were controlled. However, inhibition was a better predictor of PM performance. The discrepancy between these findings for inhibition could be due to differences in the number and types of tasks used to measure inhibitory control and PM in these studies. Ford et al.'s findings support the idea that EF may be a unitary construct at this age because inhibition and working memory were positively correlated with one another, whereas the findings of Mahy and Moses (2011) suggest that working memory and inhibition may be differentiated as they were not correlated with each other.

Some recent work has provided some encouraging data that working memory (Kretschmer et al., 2013) and inhibition (Mahy et al., 2014) play a role in the age effect in time- and event-based PM. Kretschmer et al. (2013) found that performance on working memory as measured by the backward digit span task (but not inhibition or set shifting) mediated the effect of age on time-based PM in preschool and early primary aged children. In contrast, Mahy and colleagues (2014) found that performance on inhibition as measured by the Simon Says task (but not working memory or set shifting) fully mediated the effect of age on event-based PM in 4- and 5-year-old children. It is worth noting that many of the EF measures used in these studies have both working memory and inhibitory demands, despite being labeled either working memory or inhibition tasks, which might explain some of the discrepant findings.

In sum, there is a myriad of theory and empirical evidence suggesting that EF plays an important role in PM and its development. Hence, we suggest a model of PM development that is grounded in the development of EF. It is our hope that this paper will create a novel framework in which to view research on children's PM, particularly emphasizing the distinct components of a PM paradigm, how specific aspects of EF are manipulated (whether intentionally or unintentionally) within each of these components, and what implications this has for PM in children of different ages.

\section{Executive model of prospective memory development}

Currently, there is no explicit model of PM development. Rather the literature consists mostly of isolated studies offering largely ad hoc explanations for effects. Research on children's PM is only now beginning to investigate factors predicted by the multiprocess framework or the PAM model to determine the extent that controlled processes are recruited for PM (e.g., Kliegel et al., 2013; Leigh \& Marcovitch, 2014; Mahy et al., 2014). Given the evidence suggesting the potentially important role that executive processes play in the early development of both event- and time-based prospective memory, we will describe a model of PM based on the development of specific EFs during childhood that generates predictions for the ages at which PM will be particularly affected by developing EFs.

A recent model of children's episodic memory development suggests that advances in this realm are driven by both an associative component and a more strategic component tied to development of the prefrontal cortex (Shing \& Lindenberger, 2011; Shing et al., 2010; Shing, Werkle-Bergner, Li, \& Lindenberger, 2008). Similarly, we conceptualize PM as relying on associative processes involved in retrospective memory for the intention but also on executive processes involved in carrying out the prospective intention at the appropriate time in the face of distracting ongoing activity. Our model makes three key predictions about the development of PM and the role of EF in that development.

First, our model predicts that a certain level of EF is necessary for the successful execution of a prospective intention and, as a result, very young children with underdeveloped executive skills will have poor PM. Findings that 2-year-olds struggle with PM (e.g., Kliegel \& Jäger, 2007) are consistent with this view as their EF skills are yet to undergo the rapid development of the preschool years in areas such as working memory, inhibitory control, and planning skills (e.g., Carlson, 2005). Our model suggests that, early in development, children with low EF ability will likely fail to carry out their intentions despite their accurate reporting of what they were supposed to do (i.e., intact RM; see Kliegel \& Jäger, 2007). We suggest that, for children to perform the PM task successfully, a certain level of EF 
is necessary beyond retrospective memory for the intention. Although EF may not be a prerequisite for a PM intention to be remembered (as this relies more on associative retrospective memory processes), it is a prerequisite for the PM action to be carried out. One way to test this hypothesis would be to examine the performance of children who fail to carry out the intention. If these children have remembered the intention but lack the executive ability to carry it out then we would expect to see subtle signs that they detected the PM cue, such as slowed OT performance or increased looking at the PM cue or even eye contact with the experimenter when PM cues are present. To the extent that a certain level of EF is needed for PM, we would expect that successful PM will begin to emerge around 3 years of age and greatly improve between the third and fifth years of life based on rapid increases in EF during that period (Carlson, 2005). Interestingly in this regard, a recent study showed that developmental improvements in 3- to 5-year-olds' PM were predicted by prospective processes independent of retrospective memory processes (Walsh, Martin, \& Courage, 2014), supporting our model's first prediction.

Second, beyond the early childhood years, developmental advances in EF and associated advances in prefrontal functioning should enable better PM particularly under challenging task circumstances with heavy EF demands. More specifically, development of PM is predicted to lag EF development (and associated neural changes in prefrontal areas) such that only after children's EF has advanced, should we see increases in PM performance. There is currently encouraging evidence that EF and PM are positively correlated in later childhood and into adolescence (Kerns, 2000; Shum et al., 2008), however, longitudinal studies are necessary to more strongly test this prediction. In addition, neuroimaging studies have the potential to shed more light on this prediction by examining relevant structural and functional brain changes.

Further, it is proposed that different executive processes may play more or less important roles in PM development at different stages in development given the differing developmental trajectories of various EFs. For example, early in childhood increases in basic working memory allow for children to hold prospective intentions in mind and to bring an intention into the focus of attention whereas later in childhood monitoring, complex inhibitory processes, and shifting may play especially important roles in disengaging attention from an absorbing OT. Given that simpler executive skills (e.g., basic working memory and inhibition) are more highly developed earlier than complex shifting or planning abilities (Welsh, Pennington, \& Grossier, 1991), we expect younger children (3- to 5-year-olds) to be able to bring intentions into the focus of working memory but to struggle with reliably carrying out their intention due to limited monitoring and shifting abilities that are still developing into middle childhood and beyond. This prediction is consistent with past work showing that younger children often perform poorly on PM tasks and recent evidence suggesting that working memory is associated with the development of PM in early childhood (Kretschmer et al., 2013; Mahy \& Moses, 2011). Carrying out an intention successfully may require more sophisticated monitoring and shifting skills to disengage from the ongoing task and to activate a prospective intention, especially in a task that has particularly high executive demands such as a low salience PM cue or a particularly demanding OT. Skills such as set shifting and monitoring start to rapidly improve during the middle childhood years and thus we would expect PM performance to continue to improve during these years. In fact, recent work supports the idea that set shifting skills continue to predict PM performance into early adolescence (Altgassen, Vetter, Phillips, Akgun, \& Kliegel, 2014).

Finally, certain executive skills should have a greater impact on PM during specific stages of the PM task particularly during development when executive resources can be easily taxed or overwhelmed. Evidence for this prediction would be supported by findings that working memory, inhibitory control, set shifting, and internal and external monitoring differentially impact the various phases of prospective memory laid out earlier: intention formation, intention retention over a delay, ongoing task performance, and cue detection. While demands on inhibitory control and set shifting are predicted to have a more focused impact on ongoing performance and PM cue detection, planning and working memory are expected to have a greater impact on intention formation and retention over the delay. For example, if working memory is a key process in forming and maintaining an intention over the delay as well as keeping in mind both the OT and PM task rules, then manipulations of working memory during these periods should have an especially negative impact on PM performance. 
Although our model predicts a directional relation between EF and PM (i.e., that EF drives PM development), it is possible that there could be a transactional relation between $\mathrm{EF}$ and PM development ${ }^{1}$. Given that environmental experiences affect EF (e.g., Best, 2010; Diamond \& Lee, 2011; Sarsour et al., 2011), practice on PM tasks may in fact in turn improve EF and may perhaps contribute to the specialization of the EF system. Therefore, improvement on one skill may also improve the other given that often PM tasks often rely on underlying executive skills.

\section{Future directions}

In order to test the executive framework, several research approaches are necessary. Longitudinal studies are necessary to track the development of EF and PM over time in a single group of children in order to examine how changes in EF affect later changes in PM. This would allow for the thorough testing of the prediction that PM lags EF development later in childhood. Microgenetic studies would be of particular use, as they would allow for detection of subtle changes in executive abilities and their subsequent impact on PM performance. Further, training the use of EFs in specific PM phases would be informative in teasing apart the various contributions of EFs to the different components of a PM task. Mediational studies would allow for the examination of the extent to which age-related changes in PM are underpinned by the various aspects of EF and different points in development. Finally, experimental studies that manipulate demands on different aspects of EF at different stages of the PM task would be helpful in understanding the stages in which certain EFs have the largest impact on PM. Using a combination of these approaches, the executive framework of PM could be more fully tested and elaborated.

One gap in the literature is the relative lack of time-based PM studies in younger children. The investigation of time-based PM is especially important in relation to EF because time-based PM relies more than event-based PM on monitoring of the external environment and self-initiated processes such as monitoring one's intentions. Our model would thus predict that EF would be even more strongly implicated in time based PM than event based PM. As noted earlier, time-based PM tasks have traditionally been given only to older children because of their heightened awareness of time and ability to read the time from a clock, but recently creative solutions to this challenge have been found. For example, Aberle and Kliegel (2010) examined preschoolers' time-based PM using an hourglass as a time keeper providing an alternative way to represent time so that even young children can carry out the task. Time-based PM tasks with young children will offer an opportunity to more thoroughly examine monitoring and other executive processes and the impact of their development on PM performance.

In addition, research should focus on testing developmental predictions about when certain EFs will impact PM performance based on their developmental trajectories. Our framework can be used to design experiments examining what EFs matter most at each of the four stages of PM described earlier. For example, requiring young children complete a secondary task that involves set shifting should impact their PM as their attentional resources will be over-taxed. In similar vein, training task switching ability should improve children's ability to carry out the PM intention in coordination with the ongoing task, leading to fewer tradeoffs between performance of the OT and PM tasks. Finally, individual differences in EF ability could be used to predict performance on different stages of PM tasks. For example, low- and high-EF children could be recruited in order to examine the question of whether (independent of age) difference levels of EF development predict success in PM. Currently, specific EFs have been shown to impact PM: inhibition mediates PM development in 4- and 5-year-olds (Mahy et al., 2014), working memory updating affects PM in middle childhood (Kretschmer et al., 2013), and set shifting is the best predictor of PM during early adolescence (Altgassen et al., 2014). More research is needed to investigate the relative impact of different executive functions on PM at different periods in childhood and whether this is influenced by how EF and PM are measured.

\footnotetext{
1 We thank an anonymous reviewer for raising this point.
} 


\section{Conclusion}

In sum, the development of children's PM has recently begun to receive attention after being neglected for many years while research on young adults and older adults was flourishing. The importance of PM for children increases as they age and are expected to become more independent in carrying out their own intentions. In fact, as children age forgetting to do things becomes increasingly seen as an undesirable aspect of character (i.e., they are irresponsible, lazy) rather than just a memory failure (Brandimonte \& Ferrante, 2009). Given how critical PM is for children's academic and social success, much more research is needed to investigate how this ability emerges and what is responsible for its continued development. Our hope is that this literature review, the executive framework outlined, and the model of PM development proposed will spark further interest in this area and generate innovative research to advance our understanding of this critical cognitive ability.

\section{Acknowledgments}

Preparation of the manuscript was partly funded by a Natural Sciences and Engineering Research Council of Canada Postgraduate Scholarship and a Swiss Government Scholarship to CEVM. MK acknowledges funding from the German Research Council (DFG).

\section{References}

Aberle, I., \& Kliegel, M. (2010). Time-based prospective memory performance in young children. European Journal of Developmental Psychology, 7, 419-431.

Alloway, T. P., Gathercole, S. E., \& Pickering, S. J. (2006). Verbal and visuospatial short-term and working memory in children: Are they separable? Child Development, 77, 1698-1716.

Altgassen, M., Vetter, N.C., Phillips, L.H., Akgun, C., \& Kliegel, M. (2014). Theory of mind and switching predict prospective memory performance in adolescents. Journal of Experimental Child Psychology, 127, 163-175.

Altgassen, M., Williams, T. I., Bölte, S., \& Kliegel, M. (2009). Time-based prospective memory in children with autism spectrum disorder. Brain Impairment, 10, 52-58.

Anderson, P. (2002). Assessment and development of executive function (EF) during childhood. Child Neuropsychology, 8, 71-82.

Anderson, V. A., Anderson, P., Northam, E., Jacobs, R., \& Catroppa, C. (2001). Development of executive functions through late childhood and adolescence in an Australian sample. Developmental Neuropsychology, 20, 385-406.

Atance, C. M., \& Jackson, L. K. (2009). The development and coherence of future-oriented behaviors during the preschool years. Journal of Experimental Child Psychology, 102, 379-391.

Atance, C. M., \& O'Neill, D. K. (2001). Episodic future thinking. Trends in Cognitive Science, 5, 533-539.

Baddeley, A. D., \& Longman, D. J. A. (1978). The influence of length and frequency on training sessions on the rate of learning to type. Ergonomics, 21, 627-635.

Bahrick, H. P., \& Phelps, E. (1987). Retention of Spanish vocabulary over 8 years. Journal of Experimental Psychology. Learning, Memory, and Cognition, 13, 344-349.

Best, J. R. (2010). Effects of physical activity on children's executive function: Contributions of experimental research on aerobic exercise. Developmental Review, 30, 331-351.

Best, J. R., \& Miller, P. H. (2010). A developmental perspective on executive function. Child Development, 81, 1641-1660.

Bisiacchi, P. S., Schiff, S., Ciccola, A., \& Kliegel, M. (2009). The role of dual-task and task-switch in prospective memory: Behavioural data and neural correlates. Neuropsychologia, 47, 1362-1373.

Bjorklund, D. F. (1987). How age changes in knowledge base contribute to the development of children's memory: An interpretive review. Developmental Review, 7, 93-130.

Blakemore, S. J., \& Choudhury, S. (2006). Development of the adolescent brain: Implications for executive function and social cognition. Journal of Child Psychology and Psychiatry, 47, 296-312.

Brainerd, C. J., \& Reyna, V. F. (1998). Fuzzy-trace theory and children's false memories. Journal of Experimental Child Psychology, $71,81-129$.

Brandimonte, M. A. (1991). Ricordare il futuro. Giornale Italiano di Psicologia, 3, 351-374.

Brandimonte, M. A., \& Ferrante, D. (2009). The social side of prospective memory. In M. Kliegel, M. McDaniel, \& G. O. Einstein (Eds.), Prospective memory: Cognitive, neuroscience, developmental, and applied perspectives (pp. 347-365).

Brandimonte, M. A., Ferrante, D., Feresin, C., \& Delbello, R. (2001). Dissociating prospective memory from vigilance processes? Psicológica: Revista de Metodología y Psicología Experimental, 22, 97-114.

Brandimonte, M. A., Filippello, P., Coluccia, E., Altgassen, M., \& Kliegel, M. (2011). To do or not to do? Prospective memory versus response inhibition in autism spectrum disorder and attention-deficit/hyperactivity disorder. Memory (Hove, England), 19, 56-66.

Brandimonte, M. A., \& Passolunghi, M. C. (1994). The effects of cue-familiarity, cue-distinctiveness, and retention interval on prospective remembering. The Quarterly Journal of Experimental Psychology Section A: Human Experimental Psychology, 47A, 565-587.

Burgess, P. W., Dumontheil, I., \& Gilbert, S. J. (2007). The gateway hypothesis of rostral prefrontal cortex (area 10) function. Trends in Cognitive Sciences, 11, 290-298. 
Burgess, P. W., Quayle, A., \& Frith, C. D. (2001). Brain regions involved in prospective memory as determined by positron emission tomography. Neuropsychologia, 39, 545-555.

Carlson, S. M. (2005). Developmentally sensitive measures of executive function in preschool children. Developmental Neuropsychology, 28, 595-616.

Carlson, S. M., Davis, A. C., \& Leach, J. G. (2005). Less is more: Executive function and symbolic representation in preschool children. Psychological Science, 16, 609-616.

Causey, K.B., \& Bjorklund, D.F. (2014). Prospective memory in preschool children: Influences of agency, incentive, and underlying cognitive mechanisms. Journal of Experimental Child Psychology, 127, 36-51.

Ceci, S. J., \& Bronfenbrenner, U. (1985). Don't forget to take the cupcakes out of the oven': Prospective memory, strategic time-monitoring, and context. Child Development, 56, 152-164.

Cheie, L., Miclea, M., \& Visu-Petra, L. (2013). What was I supposed to do? Effects of individual differences in age and anxiety on preschoolers' prospective memory. International Journal of Behavioral Development, 38, 52-61.

Cowan, N. (1995). Attention and memory: An integrated framework. New York, NY: Oxford University Press.

Cowan, N. (2005). Working memory capacity. New York, NY: Psychology Press.

Craik, F. I. M. (1983). On the transfer of information from temporary to permanent memory. Philosophical Transactions of the Royal Society of London. Series B, Biological Sciences, 302, 341-359.

Czernochowski, D., Horn, S., \& Bayen, U. J. (2012). Does frequency matter? ERP and behavioral correlates of monitoring for rare and frequent prospective memory targets. Neuropsychologia, 50, 67-76.

Davidson, M. C., Amso, D., Anderson, L. C., \& Diamond, A. (2006). Development of cognitive control and executive functions from 4 to 13 years: Evidence from manipulations of memory, inhibition, and task switching. Neuropsychologia, 44, 20372078.

De Luca, C. R., Wood, S. J., Anderson, V., Buchanan, J. A., Proffitt, T. M., Mahony, K., et al. (2003). Normative data from the CANTAB. I: Development of executive function over the lifespan. Journal of Clinical and Experimental Neuropsychology, 25, 242-254.

Diamond, A., \& Lee, K. (2011). Interventions shown to aid executive function development in children 4 to 12 years old. Science, 333, 959-964.

Donald, M. (1991). Origins of the modern mind: Three stages in the evolution of culture and cognition. Cambridge, MA: Harvard University Press.

Durston, S., Thomas, K. M., Yang, Y., Uluğ, A. M., Zimmerman, R. D., \& Casey, B. J. (2002). A neural basis for the development of inhibitory control. Developmental Science, 5, F9-F16.

Einstein, G. O., \& McDaniel, M. A. (1990). Normal aging and prospective memory. Journal of Experimental Psychology. Learning, Memory, and Cognition, 16, 717-726.

Einstein, G. O., McDaniel, M. A., Thomas, R., Mayfield, S., Shank, H., Morrisette, N., et al. (2005). Multiple processes in prospective memory retrieval: Factors determining monitoring versus spontaneous retrieval. Journal of Experimental Psychology. General, 134, 327-342.

Ellis, J. (1996). Prospective memory or the realization of delayed intentions: A conceptual framework for research. In M. Brandimonte, G. O. Einstein, \& M. A. McDaniel (Eds.), Prospective memory: Theory and applications (pp. 1-22). Mahwah, NJ: Lawrence Erlbaum.

Fan, J., McCandliss, B. D., Sommer, T., Raz, A., \& Posner, M. I. (2002). Testing the efficiency and independence of attentional networks. Journal of Cognitive Neuroscience, 14, 340-347.

Ford, R. M., Driscoll, T., Shum, D., \& Macaulay, C. E. (2012). Executive and theory-of-mind contributions to event-based prospective memory in children: Exploring the self-projection hypothesis. Journal of Experimental Child Psychology, 111, 468-489.

Garon, N., Bryson, S. E., \& Smith, I. M. (2008). Executive function in preschoolers: A review using an integrative framework. Psychological Bulletin, 134, 31-60.

Gathercole, S. E., Pickering, S. J., Ambridge, B., \& Wearing, H. (2004). The structure of working memory from 4 to 15 years of age. Developmental Psychology, 40, 177-190.

Guajardo, N. R., \& Best, D. L. (2000). Do preschoolers remember what to do? Incentive and external cues in prospective memory. Cognitive Development, 15, 75-97.

Henry, J. D., Terrett, G., Altgassen, M., Raponi-Saunders, S., Ballhausen, N., Schnitzspahn, K. M., et al. (2014). A 'virtual week' study of prospective memory function in autism spectrum disorders. Journal of Experimental Child Psychology (in press).

Hicks, J. L., Marsh, R. L., \& Cook, G. I. (2005). Task interference in time-based, event-based, and dual intention prospective memory conditions. Journal of Memory and Language, 53, 430-444.

Hicks, J. L., Marsh, R. L., \& Russell, E. J. (2000). The properties of retention intervals and their effect on retaining prospective memories. Journal of Experimental Psychology. Learning, Memory, and Cognition, 26, 1160-1169.

Hongwanishkul, D., Happaney, K. R., Lee, W., \& Zelazo, P. D. (2005). Hot and cool executive function: Age-related changes and individual differences. Developmental Neuropsychology, 28, 617-644.

Howe, M. L. (1991). Misleading children's story recall: Forgetting and reminiscence of the facts. Developmental Psychology, 27, 746-762.

Hughes, C., Ensor, R., Wilson, A., \& Graham, A. (2009). Tracking executive function across the transition to school: A latent variable approach. Developmental Neuropsychology, 35, 20-36.

Huizinga, M., Dolan, C. V., \& van der Molen, M. W. (2006). Age-related change in executive function: Developmental trends and a latent variable analysis. Neuropsychologia, 44, 2017-2036.

Kerns, K. (2000). The CyberCruiser: An investigation of development of prospective memory in children. Journal of the International Neuropsychological Society, 6, 62-70.

Kerns, K. A., \& Price, K. J. (2001). An investigation of prospective memory in children with ADHD. Child Neuropsychology, 7, $162-171$.

Kerr, A., \& Zelazo, P. D. (2004). Development of "hot" executive function: The children's gambling task. Brain and Cognition, 55, 148-157.

Kliegel, M., Brandenberger, M., \& Aberle, I. (2010). Effect of motivational incentives on prospective memory performance in preschoolers. European Journal of Developmental Psychology, 7, 223-232.

Kliegel, M., \& Jäger, T. (2007). The effects of age and cue-action reminders on event-based prospective memory performance in preschoolers. Cognitive Development, 22, 33-46. 
Kliegel, M., Mackinlay, R., \& Jäger, T. (2008a). Complex prospective memory: Development across the lifespan and the role of task interruption. Developmental Psychology, 44, 612-617.

Kliegel, M., Mackinlay, R., \& Jäger, T. (2008b). A lifespan approach to the development of complex prospective memory. In M. Kliegel, M. McDaniel, \& G. O. Einstein (Eds.), Prospective memory: Cognitive, neuroscience, developmental, and applied perspectives (pp. 187-216).

Kliegel, M., Mahy, C. E. V., Voigt, B., Henry, J. D., Rendell, P. G., \& Aberle, I. (2013). The development of prospective memory in young school children: The impact of ongoing task absorption, cue salience, and cue centrality. Journal of Experimental Child Psychology, 116, 792-810.

Kliegel, M., Martin, M., McDaniel, M. A., \& Einstein, G. O. (2002). Complex prospective memory and executive control of working memory: A process model. Psychologische Beitrage, 44, 303-318.

Kliegel, M., Phillips, L. H., Lemke, U., \& Kopp, U. A. (2005). Planning and realisation of complex intentions in patients with Parkinson's disease. Journal of Neurology, Neurosurgery \&' Psychiatry, 76, 1501-1505.

Kliegel, M., Ropeter, A., \& Mackinlay, R. (2006). Complex prospective memory in children with ADHD. Child Neuropsychology, 12, 407-419.

Klingberg, T., Forssberg, H., \& Westerberg, H. (2002). Increased brain activity in frontal and parietal cortex underlies the development of visuospatial working memory capacity during childhood. Journal of Cognitive Neuroscience, 14, 1-10.

Kretschmer, A., Voigt, B., Friedrich, S., Pfeiffer, K., \& Kliegel, M. (2013). Time-based prospective memory in young children Exploring executive functions as a developmental mechanism. Child Neuropsychology, 1-15. ahead-of-print.

Kurtz-Costes, B., Schneider, W., \& Rupp, S. (1995). Is there evidence for intraindividual consistency in performance across memory tasks? New evidence on an old question. In F. E. Weinert \& W. Schneider (Eds.), Memory performance and competencies: Issues in growth and development (pp. 245-262). Mahwah, NJ: Lawrence Erlbaum Associates.

Kvavilashvili, L., \& Erskine, J. (2010). The effect of reminders on event-based prospective memory: Implications for a standard laboratory paradigm. Paper presented at the 3rd International Conference on Prospective Memory, University of British Columbia, Vancouver, Canada.

Kvavilashvili, L., \& Ford, R.M. (2014). Metamemory prediction accuracy for simple prospective and retrospective memory tasks in 5-year-old children. Journal of Experimental Child Psychology, 127, 65-81.

Kvavilashvili, L., Kyle, F., \& Messer, D. J. (2008). The development of prospective memory in children: Methodological issues, empirical findings, and future directions. In M. Kliegel, M. McDaniel, \& G. O. Einstein (Eds.), Prospective memory: Cognitive, neuroscience, developmental, and applied perspectives (pp. 113-138).

Kvavilashvili, L., Messer, D. J., \& Ebdon, P. (2001). Prospective memory in children: The effects of age and task interruption. Developmental Psychology, 37, 418-430.

Lee, K., Bull, R., \& Ho, R. M. (2013). Developmental changes in executive functioning. Child Development, 84, 1933-1953.

Lehto, J. E., Juujärvi, P., Kooistra, L., \& Pulkkinen, L. (2003). Dimensions of executive functioning: Evidence from children. British Journal of Developmental Psychology, 21, 59-80.

Leigh, J., \& Marcovitch, S. (2014). The cognitive cost of event-based prospective memory in children. Journal of Experimental Child Psychology, 127, 24-35.

Luna, B., Padmanabhan, A., \& O'Hearn, K. (2010). What has fMRI told us about the development of cognitive control through adolescence? Brain and Cognition, 72, 101-113.

Mackinlay, R. J., Kliegel, M., \& Mäntylä, T. (2009). Predictors of time-based prospective memory in children. Journal of Experimental Child Psychology, 102, 251-264.

Mahy, C. E. V., \& Moses, L. J. (2011). Executive functioning and prospective memory in young children. Cognitive Development, 26, 269-281.

Mahy, C. E. V., \& Moses, L. J. (2014). The effect of retention interval task difficulty on children's prospective memory: Testing the intention monitoring hypothesis. Journal of Cognition and Development (in press).

Mahy, C.E.V., Moses, L.J., \& Kliegel, M. (2014). The impact of age, ongoing task difficulty, and cue salience on preschoolers' prospective memory performance: The role of executive function. Journal of Experimental Child Psychology, 127, 52-64.

Marsh, R. L., \& Hicks, J. L. (1998). Event-based prospective memory and executive control of working memory. Journal of Experimental Psychology: Learning, Memory, and Cognition, 24, 336-349.

Marsh, R. L., Hicks, J. L., \& Hancock, T. W. (2000). On the interaction of ongoing cognitive activity and the nature of an event-based intention. Applied Cognitive Psychology, 14, S29-S41.

Martin, B. A., Brown, N. L., \& Hicks, J. L. (2011). Ongoing task delays affect prospective memory more powerfully than filler task delays. Canadian Journal of Experimental Psychology/Revue Canadienne de Psychologie Expérimentale, 65, 48-56.

Martin, M., \& Kliegel, M. (2003). Die entwicklung komplexer prospektiver gedachtnisleistung im kindesalter (The development of complex prospective memory performance in children). Zeitschrift fur Entwicklungspsychologie Und Padagogische Psychologie $35,75-82$.

Martin, T., McDaniel, M. A., Guynn, M. J., Houck, J. M., Woodruff, C. C., Bish, J. P., et al. (2007). Brain regions and their dynamics in prospective memory retrieval: A MEG study. International Journal of Psychophysiology, 64, 247-258.

Mattli, F., Zöllig, J., \& West, R. (2011). Age-related differences in the temporal dynamics of prospective memory retrieval: A lifespan approach. Neuropsychologia, 49, 3494-3504.

Mäntylä, T., Carelli, M. G., \& Forman, H. (2007). Time monitoring and executive functioning in children and adults. Journal of Experimental Child Psychology, 96, 1-19.

Maylor, E. A., Darby, R. J., Logie, R. H., Della Sala, S., \& Smith, G. (2002). Prospective memory across the life span. In P. Graf \& N. Ohta (Eds.), Lifespan development of human memory (pp. 235-256). Cambridge, MA: The MIT Press.

McCauley, S. R., \& Levin, H. S. (2004). Prospective memory in pediatric traumatic brain injury: A preliminary study. Developmental Neuropsychology, 25, 5-20.

McDaniel, M. A., \& Einstein, G. O. (2000). Strategic and automatic processes in prospective memory retrieval: A multiprocess framework. Applied Cognitive Psychology, 14, S127-S144.

McDaniel, M. A., Glisky, E. L., Guynn, M. J., \& Routhieaux, B. C. (1999). Prospective memory: A neuropsychological study. Neuropsychology, 13, 103-110. 
McDaniel, M. A., LaMontagne, P., Beck, S. M., Scullin, M. K., \& Braver, T. S. (2013). Dissociable neural routes to successful prospective memory. Psychological Science, 24, 1791-1800.

Meacham, J. A., \& Colombo, J. A. (1980). External retrieval cues facilitate prospective remembering in children. The Journal of Educational Research, 299-301.

Meacham, J. A., \& Dumitru, J. (1976). Prospective remembering and external retrieval cues. Catalog of Selected Documents in Psychology, 6, No. 65, Ms. No. 1284.

Miyake, A., \& Friedman, N. P. (2012). The nature and organization of individual differences in executive functions four general conclusions. Current Directions in Psychological Science, 21, 8-14.

Miyake, A., Friedman, N. P., Emerson, M. J., Witzki, A. H., Howerter, A., \& Wager, T. D. (2000). The unity and diversity of executive functions and their contributions to complex "frontal lobe" tasks: A latent variable analysis. Cognitive Psychology, 41, 49100.

Moriguchi, Y., \& Hiraki, K. (2009). Neural origin of cognitive shifting in young children. Proceedings of the National Academy of Sciences, 106, 6017-6021.

Munakata, Y., Snyder, H. R., \& Chatham, C. H. (2012). Developing cognitive control: Three key transitions. Current Directions in Psychological Science, 21, 71-77.

Nieuwenhuis, S., Ridderinkhof, K. R., Kok, A., \& van der Molen, M. W. (2000). Inhibitory inefficiency and failures of intention activation: Age-related decline in the control of saccadic eye movements. Psychology and Aging, 15, 635-647.

Nigro, G., Brandimonte, M., Cicogna, P.C., \& Cosenza, M. (2014). Episodic future thinking as a predictor of children's prospective memory. Journal of Experimental Child Psychology, 127, 82-94.

Nigro, G., \& Cicogna, P. C. (2000). Does delay affect prospective memory performance? European Psychologist, 5, 228-233.

Nigro, G., Senese, V. P., Natullo, O., \& Sergi, I. (2002). Preliminary remarks on type of task and delay in children's prospective memory. Perceptual and Motor Skills, 95, 515-519.

Okuda, J., Fujii, T., Yamadori, A., Kawashima, R., Tsukiura, T., Fukatsu, R., et al. (1998). Participation of the prefrontal cortices in prospective memory: Evidence from a PET study in humans. Neuroscience Letters, 253, 127-130.

Passolunghi, M. C., Brandimonte, M. A., \& Cornoldi, C. (1995). Encoding modality and prospective memory in children. International Journal of Behavioral Development, 18, 631-648.

Perdue, B. M., Evans, T. A., Williamson, R. A., Gonsiorowski, A., \& Beran, M. J. (2013). Prospective memory in children and chimpanzees. Animal Cognition, 1-9.

Petrides, M., \& Milner, B. (1982). Deficits on subject-ordered tasks after frontal-and temporal-lobe lesions in man. Neuropsychologia, $20,249-262$.

Rendell, P. G., Vella, M. J., Kliegel, M., \& Terrett, G. (2009). Effect of delay on children's delay-execute prospective memory performance. Cognitive Development, 24, 156-168.

Sarsour, K., Sheridan, M., Jutte, D., Nuru-Jeter, A., Hinshaw, S., \& Boyce, W. T. (2011). Family socioeconomic status and child executive functions: The roles of language, home environment, and single parenthood. Journal of the International Neuropsychological Society, 17, 120-132.

Schlagmüller, M., \& Schneider, W. (2002). The development of organizational strategies in children: Evidence from a microgenetic longitudinal study. Journal of Experimental Child Psychology, 81, 298-319.

Schneider, W. (1986). The role of conceptual knowledge and metamemory in the development of organizational processes in memory. Journal of Experimental Child Psychology, 42, 218-236.

Schneider, W. (2008). The development of metacognitive knowledge in children and adolescents: Major trends and implications for education. Mind, Brain, and Education, 2, 114-121.

Scullin, M. K., McDaniel, M. A., Shelton, J. T., \& Lee, J. H. (2010). Focal/nonfocal cue effects in prospective memory: Monitoring difficulty or different retrieval processes? Journal of Experimental Psychology. Learning, Memory, and Cognition, 36, 736-749.

Shing, Y. L., \& Lindenberger, U. (2011). The development of episodic memory: Lifespan lessons. Child Development Perspectives, $5,148-155$

Shing, Y. L., Werkle-Bergner, M., Brehmer, Y., Müller, V., Li, S. C., \& Lindenberger, U. (2010). Episodic memory across the lifespan: The contributions of associative and strategic components. Neuroscience \& Biobehavioral Reviews, 34, 1080-1091.

Shing, Y. L., Werkle-Bergner, M., Li, S. C., \& Lindenberger, U. (2008). Associative and strategic components of episodic memory: A life-span dissociation. Journal of Experimental Psychology. General, 137, 495-513.

Shum, D. (2005). Prospective memory following traumatic brain injury in children and adolescents. Presentation at the Joint Mid-Year Meeting of the International Neuropsychology Society, Dublin, Ireland.

Shum, D., Cross, B., Ford, R., \& Ownsworth, T. (2008). A developmental investigation of prospective memory: Effects of interruption. Child Neuropsychology, 14, 547-561.

Simons, J. S., Schölvinck, M. L., Gilbert, S. J., Frith, C. D., \& Burgess, P. W. (2006). Differential components of prospective memory?: Evidence from fMRI. Neuropsychologia, 44, 1388-1397.

Smith, A. B., Taylor, E., Brammer, M., \& Rubia, K. (2004). Neural correlates of switching set as measured in fast, event-related functional magnetic resonance imaging. Human Brain Mapping, 21, 247-256.

Smith, G., Della Sala, S., Logie, R. H., \& Maylor, E. A. (2000). Prospective and retrospective memory in normal ageing and dementia: A questionnaire study. Memory (Hove, England), 8, 311-321.

Smith, R. E. (2003). The cost of remembering to remember in event-based prospective memory: Investigating the capacity demands of delayed intention performance. Journal of Experimental Psychology. Learning, Memory, and Cognition, 29, 347-361.

Smith, R. E., \& Bayen, U. J. (2004). A multinomial model of event-based prospective memory. Journal of Experimental Psychology. Learning, Memory, and Cognition, 30, 756-777.

Smith, R. E., Bayen, U. J., \& Martin, C. (2010). The cognitive processes underlying event-based prospective memory in school-age children and young adults: A formal model-based study. Developmental Psychology, 46, 230-244.

Smith, R. E., Hunt, R. R., McVay, J. C., \& McConnell, M. D. (2007). The cost of event-based prospective memory: Salient target events. Journal of Experimental Psychology. Learning, Memory, and Cognition, 33, 734-746.

Somerville, S. C., Wellman, H. M., \& Cultice, J. C. (1983). Young children's deliberate reminding. Journal of Genetic Psychology, 143, 87-96. 
Ślusarczyk, E., \& Niedźwieńska, A. (2013). A naturalistic study of prospective memory in preschoolers: The role of task interruption and motivation. Cognitive Development, 28, 179-192.

Talbot, K.D., \& Kerns, K.A. (2014). Event and time triggered remembering: The impact of ADHD on prospective memory performance in children. Journal of Experimental Child Psychology, 127, 126-143.

Terry, W. S. (1988). Everyday forgetting: Data from a diary study. Psychological Reports, 62, 299-303.

Voigt, B., Aberle, I., Schonfeld, J., \& Kliegel, M. (2011). Time-based prospective memory in schoolchildren. Zeitschrift für Psychologie, 219, 92-99.

Walsh, S.J., Martin, G.M., \& Courage, M.L. (2014). The development of prospective memory in preschool children using naturalistic tasks. Journal of Experimental Child Psychology, 127, 8-23.

Wang, L., Altgassen, M., Liu, W., Xiong, W., Akgün, C., \& Kliegel, M. (2011). Prospective memory across adolescence: The effects of age and cue focality. Developmental Psychology, 47, 226-232.

Wang, L., Kliegel, M., Liu, W., \& Yang, Z. (2008). Prospective memory performance in preschoolers: Inhibitory control matters. European Journal of Developmental Psychology, 5, 289-302.

Wang, L., Kliegel, M., Yang, Z., \& Liu, W. (2006). Prospective memory performance across adolescence. The Journal of Genetic Psychology, 167, 179-188.

Ward, H., Shum, D., McKinlay, L., Baker-Tweney, S., \& Wallace, G. (2005). Development of prospective memory: Based on the prefrontal-lobe model. Child Neuropsychology, 11, 527-549.

Welsh, M. C., Pennington, B. F., \& Grossier, D. B. (1991). A normative-developmental study of executive function: A window on prefrontal function in children. Developmental Neuropsychology, 7, 131-149.

West, R. (2011). The temporal dynamics of prospective memory: A review of the ERP and prospective memory literature. Neuropsychologia, 49, 2233-2245.

West, R., \& Covell, E. (2001). Effects of aging on event-related neural activity related to prospective memory. Neuroreport, 12, $2855-2858$

West, R., \& Craik, F. I. (2001). Influences on the efficiency of prospective memory in younger and older adults. Psychology and Aging, 16, 682-696.

Wiebe, S. A., Espy, K. A., \& Charak, D. (2008). Using confirmatory factor analysis to understand executive control in preschool children: I. Latent structure. Developmental Psychology, 44, 575-587.

Wiebe, S. A., Sheffield, T., Nelson, J. M., Clark, C. A., Chevalier, N., \& Espy, K. A. (2011). The structure of executive function in 3-year-olds. Journal of Experimental Child Psychology, 108, 436-452.

Williams, D., Boucher, J., Lind, S., \& Jarrold, C. (2012). Time-based and event-based prospective memory in autism spectrum disorder: The roles of executive function and theory of mind, and time-estimation. Journal of Autism and Developmental Disorders, 43, 1555-1567.

Willoughby, M. T., Blair, C. B., Wirth, R. J., \& Greenberg, M. (2010). The measurement of executive function at age 3 years: Psychometric properties and criterion validity of a new battery of tasks. Psychological Assessment, 22, 306-317.

Yang, T.-X., Chan, R. C. K., \& Shum, D. (2011). The development of prospective memory in typically developing children. Neuropsychology, 25, 342-352.

Zelazo, P. D. (2006). The dimensional change card sort (DCCS): A method of assessing executive function in children. Nature Protocols, 1, 297-301.

Zelazo, P. D., Carlson, S. M., \& Kesek, A. (2008). The development of executive function in childhood. In C. A. Nelson \& M. Luciana (Eds.), Handbook of developmental cognitive neuroscience (pp. 553-574). Cambridge, MA: MIT Press.

Zelazo, P. D., Carter, A., Reznick, J. S., \& Frye, D. (1997). Early development of executive function: A problem-solving framework. Review of General Psychology, 1, 198-226.

Zimmermann, T. D., \& Meier, B. (2006). The rise and decline of prospective memory performance across the lifespan. The Quarterly Journal of Experimental Psychology, 59, 2040-2046.

Zöllig, J., West, R., Martin, M., Altgassen, M., Lemke, U., \& Kliegel, M. (2007). Neural correlates of prospective memory across the lifespan. Neuropsychologica, 45, 3299-3314. 